Original Research Paper

\title{
A Personalized Learning Approach based on Learning Speed
}

\author{
${ }^{1}$ Hicham Aberbach, ${ }^{1}$ Adil Jeghal, ${ }^{1}$ Abdelouahed Sabri, ${ }^{1}$ Hamid Tairi and ${ }^{2}$ Loubna Laaouina \\ ${ }^{1}$ LISAC, University of Sidi Mohamed Ben Abdellah, Fez, Morocco \\ ${ }^{2}$ LISA, University of Sidi Mohamed Ben Abdellah, Fez, Morocco
}

\section{Article history}

Received: 27-12-2020

Revised: 06-03-2021

Accepted: 18-03-2021

Corresponding Author:

Hicham Aberbach

LISAC, University of Sidi

Mohamed Ben Abdellah, Fez,

Morocco

Email: aberbachhicham@gmail.com

\begin{abstract}
This learning is a process composed of several mechanisms oriented towards the acquisition of certain knowledge, whose actors are called learner and teacher, to improve the effectiveness and usefulness of learning we need to personalize the knowledge, skills and behaviors that allow for a change to a mode of education that gives diverse learning choices to the learners, where the experience is tailored to the learning preferences, specific interests and needs of each learner, we are talking here about personalized learning or adaptive learning, The best criterion that emphasizes personalized or adaptive learning is that it is valid for all levels of education. This includes students from Grade 1 through to adults studying for their career assessments, our work consists in proposing a new method of learning personalization in order to affect the learner towards the content that is appropriate to him, this method is based on the one hand, on the calculation of the learning speeds and on the other hand on the estimation of the average of these velocities using the Markov decision process. The result presented at the Test and result section shows the importance, the quality and the positive impact of this method compared to the other existing.
\end{abstract}

Keywords: Learning, Process, Adaptive Learning, Personalized Learning Personalization, Method, Learning Speed, Markov Decision Process

\section{Introduction}

A learning system needs relevant information about the learner to personalize, adapt learning to its characteristics or preferences. This information is provided by what is called: Learner Model. Historically, models of the learner are cognitive models, which mean they are representing the knowledge of the learner on a particular domain (the one to which the environment relates learning). More and more emotional models are appearing about emotions, the goals of the learners (Py and Hibou, 2006). Specify that the learner's models contain three types of information: Information of a cognitive, behavioral or psychological. This information may be knowledge, know-how, intentions or emotions (Moulet, 2005).

Information technology (Pane, 2017) has also created perspectives and opportunities to take into account the differences that exist between learners. The fundamental change in the methods and ways of acquiring knowledge, it by reinforcing these gains through social media, free access to different learning platforms, intelligent tutoring systems, or actually Personalized or adaptive learning, has given rise to a new relationship between teachers and students, between students themselves and between acquaintances and students and knowledge and teachers. Students who have access to different information technologies can adapt their learning in a much more autonomous and innovative way.

Learning (Pane, 2017) is an attitude of curiosity that goes beyond school and encourages individuals and groups to contribute to knowledge by contributing to research. Without research, it will be difficult to ensure successful learning, because while schools provide students with a great deal of pre-established knowledge, in order to apply it and continue to acquire new knowledge, students must embody the spirit of research. The teacher must show a genuine interest in students' ideas and never stop thinking that is driven by curiosity but that deviates from the learning objectives. Research, like creativity, requires a certain amount of risk-taking. For the learning experience to be truly personalized, both student and teacher must be researchers.

Personalized learning is the set of methods, processes of adaptation of teaching activities, learning paths, intended to meet the specificities and personal needs of learners, it is a form of integral adaptation that involves the learner completely. 
In this article, we discuss a set of approaches dedicated to personalization of learning; we present our learning system with a new method of personalization learning based on the Markov decision process and which will have as objective to calculate the average speed of learning, through several input values and this to eventually come to adjust the level of activities that can be offered to a learner based on its performance and capacity, Educators have long known that learning improves when teaching is personalized, tailored to individual learning styles, Personalized learning is a strong message aimed at enabling the learner to take ownership of the learning process in order to learn throughout his or her life.

\section{Related Works}

We can define the personalized learning, as an adaptation of pedagogical resources in a teaching context, based on the optimization of the pace of learning and the pedagogical approach to meet the needs of learners. We are therefore talking about a teaching method where the learner chooses the content that seems appropriate to him after conducting a specific activity.

The concept of personalization of learning includes individualization of teaching, where the student can advance at his own pace and that of learning, differentiation, where he can choose between different learning methods according to his needs, preferences and his own characteristics. Personalization is increasingly developing in an environment where, as well, learning objectives and supports varies, such as a teaching method and pace, depending on the choices of the learner.

Research shows that adult learners when they control the nature, duration and direction of learning processes, become increasingly motivated. Then adult learners need to decide what to learn and when based on their needs. or even more, they will then have the opportunity to manage their schedule well in order to find other modules to study or effective and quick solutions to their complications (Pane, 2017). Some challenges are hampering the development of personalized learning like: Teachers reported the major challenges they face in implementing customized learning solutions. They are confused between managing priorities and time to ensure that learners are able to assimilate everything they need, all due to poor integration of data systems, contractions between skills-based habits and adherence to educational standards at the school level and the time needed to design personalized courses.

In this section we will represent some approaches of personalized learning. The Unified Personalization of Learning Activities model (Lefevre et al., 2011) allows teachers to define a pedagogical strategy associated with a context of use. The pedagogical strategy provides insights into learner information, criteria and conditions for better assigning activities to them. This assignment is described using a set of hierarchical links called assignment rules. The context of use includes the circumstances, the constraints related to the environment in which the session takes place, for example (duration of the session, the number of exercises...), the Generics models and processes to Personalize learners (Lefevre, 2010) called GEPPETOP approach, this approach is based on generic models and processes in order to adapt learning activities to teachers' teaching standards. This approach allowed not only an adaptation of paper activities (GEPPETOP) but also software activities within LEIs (GEPPETOS). The two divisions of the approach were implemented in «Adapte», a perception that offers each learner activities adapted to his profile, while respecting the pedagogical choices of his teacher. Szilagyi et al. (2011), the principle of this approach is based on an active and semantic learning system. This system is part of the current context marked by the development of this daily practice of content sharing related to the social web and the evolutions of the semantic web. It allows the possibility to offer educational supplements "found" on the web in an "intelligent" way, which will contribute to the constitution of personalized training courses. Its main objective is to select the best pedagogical resources or we can consider it as a pedagogical object to support the learning of the learner.

Markov Approach (Daubigney et al., 2011): Uses in a first part the decision-making processes of the Markov chain and in a second one reinforcement learning to schedule the activities and adopt courses to each student, this approach allows to the learner the possibility to find the sequence that will statistically make it progress better, (Soulef and Abdesselam, 2016): This approach is a recommendation method based on a hybrid filtering allowing a multi-criteria personalization of the educational content and give possibility to predict the utility of an item for a given learner taking into account three factors: His interests, his level and the capacity memory or ability to retain acquired information, (Soulef and Abdesselam, 2016). An adaptive ubiquitous learning system is a system that adapts at each moment and period to the requirements of the learning profile and its context. The physical, virtual and logical sensors allow acquiring the contextual information about the learner, the creation of the personalized course, suitable for each learner is carried out by the system itself; This approach aims to offer adapted course materials, taking into consideration learning styles and environments. This method supports learners through courses and teaching materials created by an adaptive engine based on rules implemented. El Guabassi et al. (2018): This approach presents a solution that integrates the concepts of social media and knowledge management allowing students, teachers and external experts (most of the times these can be future employers) to create an environment for 
educational work in a collaborative interdisciplinary space within and outside the institutional sphere. Sfenrianto et al. (2018): Learners tend to have the same precursors, skills and requirements and this is applied in traditional English language learning approaches. This approach offers a level of knowledge of Adaptive Learning Systems (ALS-KL), it is a system that gives an opportunity to customize the teaching materials according to the level of competence that each English language learner has. Anton and Shikov (2018): This method targets the personal traits of each individual or employee in a company in order to better motivate employees and ensure an improvement in the quality of training for specialist agents in the different areas of the different companies. this approach is intended for companies that find it difficult to offer their employees a high and continuous motivation, it gives a formula that contains a clear need for the operation of detecting the desires of employees for a change of position, either vertical or horizontal and also to manage the changes for a single interest, that of the company (Chookaew et al., 2014). We can present this method as an innovative personalized e-learning environment to promoting students' learning on the topic Basic Computer Programming for undergraduate students. This developed e-learning environment could help students gain more conceptual knowledge on the topic and they had positive attitude toward learning in this e-learning environment, also it plays an important role in enhancing the effectiveness of the entire elearning environment. Concept of expert system for creation of personalized, digital skills learning pathway (Różewski et al., 2019) this system is the user path, which consists of the ordered set of project, the system runs on the DigComp framework to generate the user path, which consists of the ordered set of project learning resources from Digital Skills Accelerator. Selected resources best fit user's digital skills profile and will help in raising his/her digital competence, (Huang, 2011): This personalized learning system was constructed based on personalized Knowledge Structural Graph (KSG) by the artificial intelligence, the data mining and the database technology. The system can dynamically assess the learning process to produce personalized KSG based on different learners. The Optimal Learning Path (OLP) generator was designed and implemented based on personalized KSG through the topological sort algorithm, in order to provide learners personalized learning content and teaching methods. In addition, the system can also dig for the learning history data and gain the knowledge to improve personalized service decision-making rules and student model of the system. The experiments show that it greatly increases the efficiency of e-learning. Srivastava and Haider, (2017): This approach provides a personalized assessment model for alphabet learning with learning objects for children's who face dyslexia.
The cognitive inclination of dyslexic learner has been determined using assessment model. This paper studies the cognitive potential of dyslexic learner and has built a personalized e-learning platform to alleviate their alphabetical problems, (Kar et al., 2019) the proposed approach focuses on referral systems which will enable the needs and preferences of individuals and user groups to be assimilated through an overview of the data presented in the form of history and subsequently provide recommendations for intelligent lighting control of buildings. This approach enables efficient control of personalized light by supporting on the one hand the paradigms of intelligent buildings and predicting the individual preferences of the user (Gómez et al., 2014). The learning system presented is an adaptive and personalized mobile pedagogical design that takes into accounts the context and the learning environment, to quote the learning units of the Mobile Reader (UoLmP), the objective of which is to ensure the semi-automatic adaptation of learning pathways and activities. The results of experimentation with this approach show that UoLmP effectively adapts the learning process of an educational scenario with learning materials, finally, these customizations and adaptations help learners to carry out learning activities well (Tsolis et al., 2010). It's an adaptive and personalized e-Learning system which is based on open source software and technologies. Adaptation and personalization received very little coverage in e-learning platforms. An e-learning course should not be designed without matching students' and teachers' needs and objectives as closely as possible and without adapting during course progression. The proposed open source e-learning system offers profiling and personalization services for the teacher and student while at the same time adapts the educational content and tools in the basis of the acquired user's profile. Yarandi et al., (2013): The goal is to develop a personalized e-learning approach which creates adaptive content based on learner's abilities, learning style, level of knowledge and preferences. In the approach, ontology is used to represent the content, learner and domain models. The learner model describes learner's characteristics required to deliver tailored content. The domain model consists of some classes and properties to define domain topics and semantic relationships between them. The content model describes the structure of courses and their components. The personalized content containing a number of different Instructional Objects which is tailored to a particular learner based on information in the learner model. The response of the learner to some regular tests during the learning process is analyzed by the item response theory to evaluate the ability of learner. The system recognizes changes in the learner's level of knowledge as they progress. 
Accordingly, the learner model is updated based on learner's progress and the passage from one stage of learning process to the next stage is determined based on the updated learner's profile. Rahman and Abdullah (2018) it's a personalized group-based recommendation approach for Web search in e-learning. The primary motivation is to present an adaptive e-learning method for students of different learning capabilities when using the popular search engines. To achieve this, a Web search recommender system was developed as a gateway between the Google search engine and the institutional elearning portal so as to enable the search engine to deliver personalized search results as recommendations for students based on their individual needs.

This system (Rahman and Abdullah, 2018) is employed in the educational institutional environment where student data can be obtained from the Students' Management Information System. This therefore enriches the data of the students to construct rich user profile. By utilizing a rich user profile and by identifying students with similar learning potential and attitude, the search engine can provide a more personalized recommendation of the search result.

All the methods and approaches presented above lack concentration on the learner's need, these characteristics and especially its rate of learning, which is the key to the success and total completion of a learning journey.

\section{Proposed Model: (Learning Speed Method)}

Our method is called Learning Speed Method; it was built on Markov Decision Process, for the impressive results of this method, the recommendations for use as well as the degree of effectiveness approved in several projects and researches.
As we noted in the previous section, there are several methods of learning customization, in this article, we will present our approach to personalization of learning based on learning speed's value in order to appropriate the right content for each type of learner, we talk here about adaptive learning content. In another way the purpose of our method is to provide an estimate average speed of learning based on Markov Decision Process and that to help our learning system to affect courses with adapted content for each learner.

\section{A. Description of Our System}

At the stage of the provision of a course by the tutor, our system asks him to plan the course at least on three levels, named L1, L2, L3: The first is very well detailed, the second well detailed and the third detailed, each level consists of one or more chapter designated by $\mathbf{C m}$, with $\mathbf{1}<\mathbf{m}<\mathbf{j}$ (max number of chapter), the difference between these three levels is based on the number of examples and exercises intended for the acquisition of a knowledge, this model requires the following conditions:

- Each course must have at least three levels

- Each level must have at least three chapters

- The tutor estimates the time needed to complete each chapter

The Table 1 summarizes this presentation:

$$
L i: 1<i<n, C j: 1<j<m,
$$

$\mathbf{T L}_{\mathbf{n}} \mathbf{C}_{\mathbf{j}}$ : time needed to complete the chapter $\mathrm{j}$ of the level $\mathrm{n}$, with i: Number of Level, j: Number of Chapter.

Table 1: Level and chapters

\begin{tabular}{lllll}
\hline Chapter/Level & $\mathrm{L}_{1}$ & $\mathrm{~L}_{2}$ & $\mathrm{~L}_{\mathrm{i}}$ & \\
\hline $\mathrm{C}_{1}$ & $\mathrm{~T}_{\mathrm{L} 1 \mathrm{C} 1}$ & $\mathrm{~T}_{\mathrm{L} 2 \mathrm{C} 1}$ & $\mathrm{~T}_{\mathrm{LiC} 1}$ & $\mathrm{~T}_{\mathrm{LnC1}}$ \\
$\mathrm{C}_{2}$ & $\mathrm{~T}_{\mathrm{L} 2 \mathrm{C2}}$ & $\mathrm{T}_{\mathrm{L} 2 \mathrm{C} 2}$ & $\mathrm{~T}_{\mathrm{LiC2}}$ & $\mathrm{T}_{\mathrm{LnC2}}$ \\
$\mathrm{C}_{\mathrm{j}}$ & $\mathrm{T}_{\mathrm{L} 1 \mathrm{Cj}}$ & $\mathrm{T}_{\mathrm{L} 2 \mathrm{Cj}}$ & $\mathrm{T}_{\mathrm{LiCj}}$ & $\mathrm{T}_{\mathrm{LnCj}}$ \\
\hline
\end{tabular}

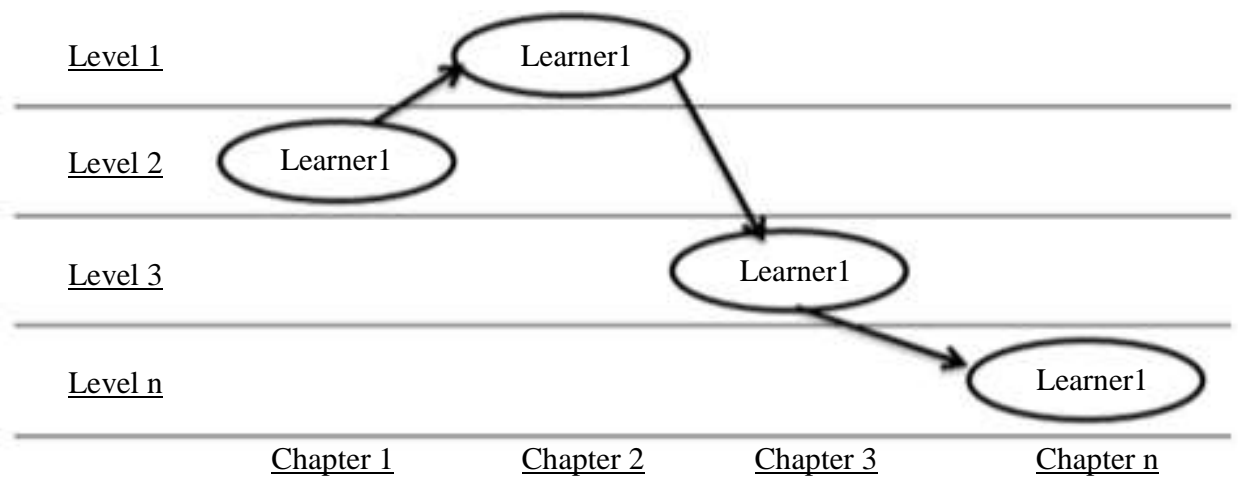

Fig. 1: System conception 


\section{Problematic}

Our problem consists on the one hand to detect the level of the learner based on our developed approach, which gives as result and as result or output element a learning speed and on the other hand to assign this learner to the level learning appropriate to him.

\section{A. Principe of Our Method}

This Fig. 1 represents a design which gives an idea on the functioning of our system, shows the evolution that a learner can have during a complete learning path.

\section{Step 1}

To make a decision to guide the learner to the appropriate level, we will first calculate the specific learning speed for each chapter with the following equation:

$$
(\text { TCjLn }=\text { Tcj passed } / \text { Tcjestimated })
$$

So in general way the calculation of the learning speed according to the following equation:

$$
L(\text { speed })=\text { Time Elapsed } / \text { Estimated Time }
$$

With:

$T_{L n C j}$ : $\quad$ Learning speed for chapter $j$ of level $n$.

$T_{\text {Cjpassed: }}$ Time spent for the chapter $j$ of the selected level

$T_{\text {ci estimated: }}$ Estimated time for the chapter $j$ of the selected level.

Step 2

- If $0<T_{C j L n} \leqslant T_{0}$ we will recommend to the learner to follow the course of the level 3

- If $T_{0}<T_{C j L n} \leqslant T_{1}$ we will recommend to the learner to follow the course of the level 2

- If $\boldsymbol{T}_{1}<T_{C j L n} \leqslant T_{2}$ we will recommend to the learner to follow the course of the level 1

- If $\mathrm{T}_{\mathrm{cj} \mathrm{Ln}}>1$, no level change

\section{Knowing that}

$$
\begin{aligned}
& \mathrm{T} 0=\operatorname{Tn}(\mathrm{L} 3) / \operatorname{Tn}(\mathrm{L} 1), \mathrm{T} 1=\operatorname{Tn}(\mathrm{L} 3) / \mathrm{Tn}(\mathrm{L} 2), \\
& \mathrm{T} 2=\operatorname{Tn}(\mathrm{L} 3) / \operatorname{Tn}(\mathrm{L} 3) . \\
& \text { In a general way } \\
& \text { T0 = Tcj estimated }(\mathrm{Ln}) / \mathrm{Tcj} \text { estimated }(\mathrm{Ln}-2) \\
& \text { T1 = Tcj estimated }(\mathrm{Ln}) / \mathrm{Tcj} \text { estimated }(\mathrm{Ln}-1) \\
& \text { T2 = Tcj estimated }(\mathrm{Ln}) / \mathrm{Tcj} \text { estimated }(\mathrm{Ln}) \\
& \text { - j number of chapter, } \mathrm{n} \text { means the level. }
\end{aligned}
$$

\section{Step 3}

Then, we will interpret the results and obtain the learning speeds for each chapter for a given learner, which will allow us to deduce the average learning speed which gives us a possibility to make decision support in the learning systems.

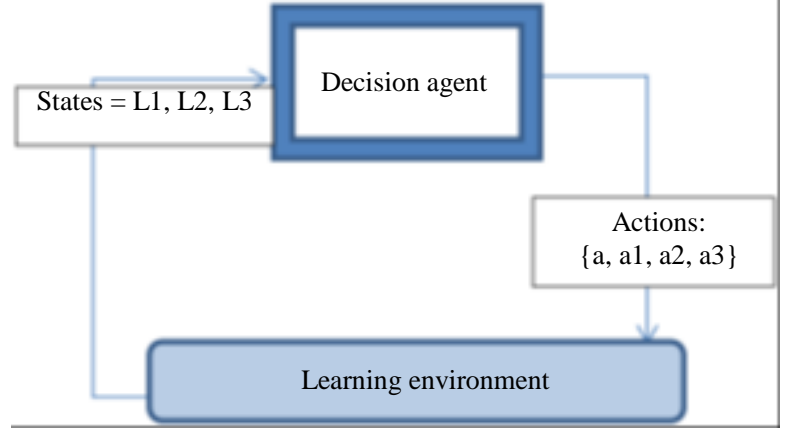

Fig. 2: Learning system

We will apply a technique that consists of setting up an agent that supports decisions and results based on a random sequence of actions or states; we call this method in decision theory and probability: A Markov Decision Process (MDP).

A Markov decision process is a general model for a stochastic environment in which an agent can make decisions and receive rewards; Modeling decisionmaking situations equal the uncertain.

Over the years, they have proven their utility in a wide variety of fields, such as finance, Engineering, ecology, human resources and learning technologies. A MDP is defined by:

- A set of states' S (including an initial being s0)

- A set of possible Actions (S) when I am in state $S$

- A transition model P(s'|s, a) or a belongs to A (s)

- A reward function $\mathrm{R}$ (s) (utility to be in state $\mathrm{S}$ )

$S=\{L 1, L 2, L 3\}$

$\operatorname{Actions}(s)=[\mathrm{a}, \mathrm{a} 1, \mathrm{a} 2, \mathrm{a} 3]$

\section{Knowing that}

a1: Go to Level 1, a2: Go to Level 2, a3: Go to Level 3 , a: Stay in the same level.

This Fig. 2 shows us the different players in our learning system as well as the decisions that can be made throughout the learning journey.

Based on the action taken and the state $\mathrm{S}$ we will give a reward which is described in the following way:

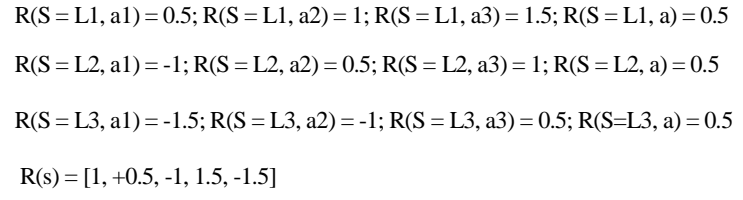

(2) $\left\{\begin{array}{l}X 1+\frac{3}{2} x 2-\frac{3}{2} x 3=0 \\ \frac{1}{2} X 1-\frac{3}{2} x 2+\frac{3}{2} x 3=0 \\ X 1+x 2+\frac{1}{2} x 3=0\end{array} \quad \Delta=\left|\begin{array}{ccc}1 & 3 / 2 & -3 / 2 \\ 1 / 2 & -3 / 2 & 3 / 2 \\ 1 & 1 & 1 / 2\end{array}\right|=\frac{-27}{8}\right.$ 
The agent selects a policy using the reward function. This results in the following equation:

$\mathbf{r}(\mathbf{s})=\mathbf{R}\left(\mathbf{L}_{\mathbf{n}}, \mathbf{a j}, \mathbf{L n}_{+\mathbf{1}} / \mathbf{L}_{\mathbf{n}-\mathbf{1}}\right) ; \mathrm{L}$ : level, a: action

A decision is a choice of an action in a state. The diagram above represents a distinct three-state Markov Decision process $\{\mathrm{S} 1=\mathrm{L} 1, \mathrm{~S} 2=\mathrm{L} 2, \mathrm{~S} 3=\mathrm{L} 3\}$ represented in blue, from each of the states, we can perform an action on the set. The red nodes thus represent a possible decision (the choice of an action in a given state).

In this Fig. 3 the value 0.5 means that the learner will remain in the same level no evolution, for +1 evolution for the next level, -1 return to the low level compared to his level, -1.5 return to level n-2 compared to his level, for the value 0 the learner did not pass through the educational path.

The numbers on the arrows are actions or decisions to be made. Finally, transitions can generate rewards (drawn here in yellow):

- We propose that the learner has gone through all the chapters of the course, which gave us a list of the following rewards:

$$
[1,1.5,-1.5,+1.5,-1.5]
$$

- Based on these values and based on the Markov decision process we obtain the following matrix:

$$
A=\left(\begin{array}{ccc}
\mathrm{L} 1 & \mathrm{~L} 2 & \mathrm{~L} 3 \\
1 & 1.5 & -1.5 \\
0.5 & -1.5 & +1.5 \\
1 & 1 & 0.5
\end{array}\right)
$$

- For the null values on the matrix we will use the value 0.5 which means for our system that the learner is not allowed to change the level, so the reward will be 0.5

- The result of this matrix will be the average and learning speed

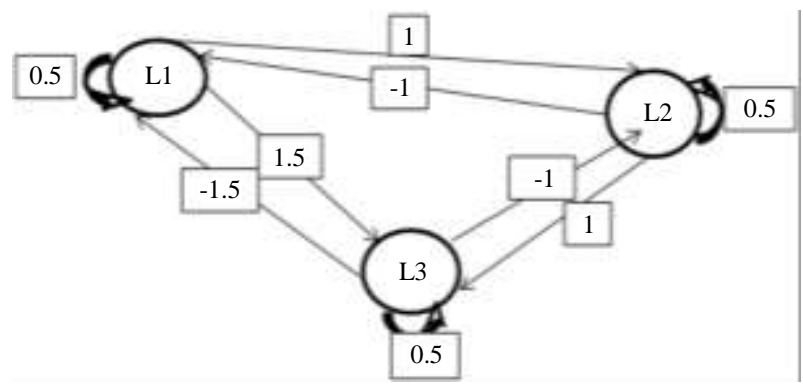

Fig. 3: Scheme of rewards
As a method of solving this matrix we chose "the method of Cramer":

$\mathrm{Xn}$ refers to the awards affected to each level of learning.

The solution of (2) with Cramer's method gave us a value that is equal $\frac{27}{8}=3.75$.

This value will be the average of the learning speed appropriate to this learner, through which we can classify and integrate this learner in the next courses associated with his learning speed.

The learning base:

$$
T_{C i L 1}, T_{C i L 2}, T_{C i L 3}, T_{\text {CiLn passed }}, T_{\text {CiLnestimated }}
$$

With $T_{C i L n}=T_{C i L n \text { passed }} / T_{\text {CiLn estimated }}$

$T_{C i L 1}$ : average speed time of learning for the chapter $i$ of level 1

$T_{C i L 2}$ : average speed time of learning for the

$T_{C i L 3}$ : $\quad$ average speed time of learning for the chapter $i$ of level 3

$T_{\text {CiLn passed: }}$ Time passed for the chapter $i$ of the level selected

$T_{\text {CiLn estimated }}$ : Estimated time for the chapter $i$ of the level selected

\section{Test and Result: (Experimentation)}

We take for the test and result part the TCiLn estimated durations for a course established on three levels L1, L2 and L3 as shown in the following Table 2:

$$
\begin{aligned}
& \mathrm{T}_{\mathrm{cjL}} \mathrm{L}_{\mathrm{n}}=\left(\mathrm{T}_{\mathrm{cjLn}}(\text { time spent }) / \mathrm{T}_{\mathrm{cjLn}}(\text { average time })\right) \\
& \mathrm{T}_{\mathrm{c} 1 \mathrm{~L} 1}=(30 \text { minutes }) /(50 \mathrm{~min})=0.6
\end{aligned}
$$

The application of our method on the durations of the example, allowed us to reach the following results:

- $\quad 0<T_{c j L n} \leqslant 0.44$, assignment to level 3

- $0.44<T_{c j L n} \leqslant 0.66$, assignment to level 2

- $0.66<T_{c j L n} \leqslant 1$, assignment to level 1

- $\quad T_{c j L n}>1$, no level change.

The value obtained in the first step indicates that the learner must be oriented towards level the following Tables 3 to 6 presents the rest of the results of the experimentation with the different assignment chapters.

This Fig. 4 corresponds to a graphic representation of the results of the experiment applied to four learners.

Table 2: Estimated duration of each chapter

\begin{tabular}{llll}
\hline Chapter/Level & $\mathrm{L}_{1}$ & $\mathrm{~L}_{2}$ & $\mathrm{~L}_{3}$ \\
\hline $\mathrm{C}_{1}$ & $50 \mathrm{mn}$ & $30 \mathrm{mn}$ & $20 \mathrm{mn}$ \\
$\mathrm{C}_{2}$ & $40 \mathrm{mn}$ & $20 \mathrm{mn}$ & $15 \mathrm{mn}$ \\
$\mathrm{C}_{3}$ & $25 \mathrm{mn}$ & $15 \mathrm{mn}$ & $10 \mathrm{mn}$ \\
$\mathrm{C}_{4}$ & $25 \mathrm{mn}$ & $10 \mathrm{mn}$ & $15 \mathrm{mn}$ \\
\hline
\end{tabular}


Table 3: Estimated duration of each chapter

\begin{tabular}{llll}
\hline Chapter $\left(\mathrm{C}_{\mathrm{n}}\right)$ & Time spent $\left(\mathrm{T}_{\mathrm{n}}\right)$ & Average time (maximum) & Learning speed $\left(\mathrm{T}_{\mathrm{ciLn}}\right)$ \\
\hline $\mathrm{C}_{1}\left(\mathrm{~L}_{1}\right)$ & $30 \mathrm{mn}$ & $50 \mathrm{mn}$ & 0.60 \\
$\mathrm{C}_{2}\left(\mathrm{~L}_{2}\right)$ & $15 \mathrm{mn}$ & $20 \mathrm{mn}$ & 0.75 \\
$\mathrm{C}_{3}\left(\mathrm{~L}_{1}\right)$ & $10 \mathrm{mn}$ & $25 \mathrm{mn}$ & 0.40 \\
$\mathrm{C}_{4}(\mathrm{~L} 3)$ & $20 \mathrm{mn}$ & $25 \mathrm{mn}$ & 0.80 \\
\hline
\end{tabular}

Table 4: Estimated duration of each chapter

\begin{tabular}{llll}
\hline Chapter $\left(\mathrm{C}_{\mathrm{n}}\right)$ & Time spent $\left(\mathrm{T}_{\mathrm{n}}\right)$ & Average time (maximum) & Learning speed $\left(\mathrm{T}_{\text {ciLn }}\right)$ \\
\hline $\mathrm{C}_{1}\left(\mathrm{~L}_{1}\right)$ & $60 \mathrm{mn}$ & $50 \mathrm{mn}$ & 1.50 \\
$\mathrm{C}_{2}\left(\mathrm{~L}_{2}\right)$ & $23 \mathrm{mn}$ & $20 \mathrm{mn}$ & 1.15 \\
$\mathrm{C}_{3}\left(\mathrm{~L}_{1}\right)$ & $26 \mathrm{mn}$ & $25 \mathrm{mn}$ & 1.30 \\
$\mathrm{C}_{4}(\mathrm{~L} 3)$ & $26 \mathrm{mn}$ & $25 \mathrm{mn}$ & 1.04 \\
\hline
\end{tabular}

Table 5: Estimated duration of each chapter

\begin{tabular}{llll}
\hline Chapter $\left(\mathrm{C}_{\mathrm{n}}\right)$ & Time spent $\left(\mathrm{T}_{\mathrm{n}}\right)$ & Average time (maximum) & Learning speed $\left(\mathrm{T}_{\text {ciLn }}\right)$ \\
\hline $\mathrm{C}_{1}\left(\mathrm{~L}_{1}\right)$ & $15 \mathrm{mn}$ & $50 \mathrm{mn}$ & 0.30 \\
$\mathrm{C}_{2}\left(\mathrm{~L}_{2}\right)$ & $25 \mathrm{mn}$ & $20 \mathrm{mn}$ & 1.75 \\
$\mathrm{C}_{3}\left(\mathrm{~L}_{1}\right)$ & $20 \mathrm{mn}$ & $25 \mathrm{mn}$ & 0.80 \\
$\mathrm{C}_{4}(\mathrm{~L} 3)$ & $18 \mathrm{mn}$ & $25 \mathrm{mn}$ & 0.72 \\
\hline
\end{tabular}

Table 6: Estimated duration of each chapter

\begin{tabular}{llll}
\hline Chapter $\left(\mathrm{C}_{\mathrm{n}}\right)$ & Time spent $\left(\mathrm{T}_{\mathrm{n}}\right)$ & Average time (maximum) & Learning speed $\left(\mathrm{T}_{\text {ciLn }}\right)$ \\
\hline C1 (L1) & $35 \mathrm{mn}$ & $50 \mathrm{mn}$ & 0.70 \\
C2 (L2) & $15 \mathrm{mn}$ & $20 \mathrm{mn}$ & 0.75 \\
C3 (L1) & $10 \mathrm{mn}$ & $25 \mathrm{mn}$ & 0.40 \\
C4(L3) & $15 \mathrm{mn}$ & $25 \mathrm{mn}$ & 0.60 \\
\hline
\end{tabular}

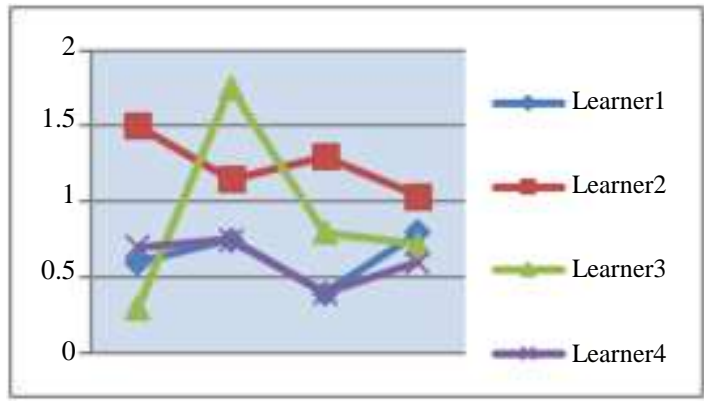

Fig. 4: Trend graph of the experience of the four learners

\section{Discussion and Interpretation}

In the wake of the discussion section, we will analyze, interpret and discuss the results found in the Test and results part, we will also fly over the course during this experience for the four learners.

In chapter $\mathrm{C} 1$ the learner a1 has spent 30 min giving a speed of 0.6 , in this case it must be assigned to level 2 to continue the course:

$$
\mathrm{R}(\mathrm{s}=\mathrm{L} 1 / \mathrm{C} 1, \mathrm{a} 2)=1 ;
$$

After the assignment at level 2, the learner spent 15 min on chapter 2 of the same level 2 which gives 0.75 as a learning speed and then consequently he is oriented to level 1 which he spent 23 min with a speed of 0.92 .
$\mathrm{R}(\mathrm{S}=\mathrm{L} 2 / \mathrm{C} 2, \mathrm{a} 1)=-1, \mathrm{R}(\mathrm{S}=\mathrm{L} 1 / \mathrm{C} 3, \mathrm{a} 3)=+1.5$, $\mathrm{R}(\mathrm{s}=\mathrm{L} 1 / \mathrm{C} 4, \mathrm{a})=0.5$.

The second table shows the path of the learner a2, according to this course he obtains the following rewards:

$\mathrm{R}(\mathrm{s}=\mathrm{L} 1 / \mathrm{C} 1, \mathrm{a})=0.5, \mathrm{R}(\mathrm{s}=\mathrm{L} 1 / \mathrm{C} 2, \mathrm{a})=0.5$,

$\mathrm{R}(\mathrm{s}=\mathrm{L} 1 / \mathrm{C} 3, \mathrm{a})=0.5, \mathrm{R}(\mathrm{s}=\mathrm{L} 1 / \mathrm{C} 4, \mathrm{a})=0.5$.

The third table concerns the path of the learner a3; we have as results of this experiment the following data:

$\mathrm{R}(\mathrm{s}=\mathrm{L} 1 / \mathrm{C} 1, \mathrm{a} 3)=1.5, \mathrm{R}(\mathrm{s}=\mathrm{L} 3 / \mathrm{C} 2, \mathrm{a})=0.5$,

$\mathrm{R}(\mathrm{s}=\mathrm{L} 3 / \mathrm{C} 3, \mathrm{a} 1)=-1.5, \mathrm{R}(\mathrm{s}=\mathrm{L} 1 / \mathrm{C} 4, \mathrm{a} 1)=0.5$.

The fourth contains the data obtained for the learner a4:

$\mathrm{R}(\mathrm{s}=\mathrm{L} 1 / \mathrm{C} 1, \mathrm{a} 1)=1.5, \mathrm{R}(\mathrm{s}=\mathrm{L} 1 / \mathrm{C} 2, \mathrm{a} 1)=0.5$,

$\mathrm{R}(\mathrm{s}=\mathrm{L} 1 / \mathrm{C} 3, \mathrm{a} 3)=1.5, \mathrm{R}(\mathrm{s}=\mathrm{L} 3 / \mathrm{C} 4, \mathrm{a} 2)=-1$.

Based on these data from experimentation.

We find the velocity values:

$$
\mathrm{V}_{1}=0.6, \mathrm{~V}_{2}=0.75, \mathrm{~V}_{3}=0.4, \mathrm{~V}_{4}=0.8
$$

These values represent the input variables in our system that will give us an output value corresponding to the average of learning speed for the learner in question: 
Table 7: Final assignment of learners

\begin{tabular}{ll}
\hline Learners & Level affected \\
\hline a1 & L3 \\
a2 & L1 \\
a3 & L3 \\
a4 & L1 \\
\hline
\end{tabular}

We will translate the found values into a matrix:

$$
\begin{aligned}
& A(a 1)=\left(\begin{array}{ccc}
1 & -1 & 0.5 \\
1.5 & 0.5 & 0.5 \\
0.5 & 0.5 & 0.5
\end{array}\right) \quad A(a 2)=\left(\begin{array}{lll}
0.5 & 0.5 & 0.5 \\
0.5 & 0.5 & 0.5 \\
0.5 & 0.5 & 0.5
\end{array}\right) \\
& A(a 3)=\left(\begin{array}{ccc}
1.5 & -1 & 0.5 \\
0.5 & 0.5 & -1.5 \\
0.5 & 0.5 & 0.5
\end{array}\right) \quad A(a 4)=\left(\begin{array}{ccc}
1.5 & -1 & -1 \\
0.5 & 0.5 & 0.5 \\
1.5 & 0.5 & 0.5
\end{array}\right)
\end{aligned}
$$

As a method of solving this matrix we chose "the method of Cramer":

The solution with Cramer's method gave us values that are equal to:

$$
\begin{aligned}
& A(a 1)=\frac{3}{4}=0.75 \quad A(a 2)=0 \\
& A(a 3)=\frac{5}{2}=2.5, \quad A(a 4)=0
\end{aligned}
$$

From these values that correspond to the average of the learning speed appropriate to each learner, we will classify and integrate learners into the following levels.

From all this as shown in Table 7 we manage to assign each learner to the level appropriate to his learning pace.

The results we found through our approach show how effective our proposed system is in tailoring learning to the different work related to this discipline.

\section{Conclusion}

In personalized learning the primary role of the teacher is to give the learners the opportunity to lead the learning path themselves, they are responsible for setting educational objectives that meet the needs of the student by always maintaining a vision ahead of the student. So the main objective of learning or education is to improve the skills and knowledge of the learner, who then goes, in turn, to participate in the development of society; without challenges the development remains impossible, all this leads us not to consider personalized learning as a comforting track without challenges in which the teacher offers the conduct of learning processes to the learners without leaving this comfort track, In order to achieve effective education on all levels of learning, this learning must be adapted and personalized, impossible to follow learning sessions well without having a vision on the intended purpose of this learning operation and does this learning just meet the need and is what it applies to the personal situation, so to be successful in education is to put it into practice and fully involve itself in the learning processes; Adapted learning helps to block the causes of abandonment of the learning paths, highlights the interest of the course and increases the total completion rate of the courses, our mission is to propose a new approach to personalized learning in order to guide the learner towards the appropriate content and teaching material, this method is based on the calculation of learning speeds and on the estimation of the average of these speeds by the Markov decision process. The result presented at the Test and result section shows the importance, the quality and the positive impact of our method compared to the other existing.

This method will be an effective solution to adapt and personalize the courses for students of different levels to lead in the end to better learning, affect to each group of learners at the level appropriate to their prerequisites and learning skills. This document present a new method for the adaptation of a learning system, which meets the goals and needs of each learner to direct him to the most appropriate level for him according to his characteristics, ability and speed of learning, our method takes into account all these criteria and meets the needs of the learner with total satisfaction, this approach is beneficial and useful for future research in personalized learning, as a future work we are working on implementations of our approach on different learning management systems.

\section{Author's Contributions}

All authors equally contributed in this work.

\section{Ethics}

This article is original and contains unpublished material. The corresponding author confirms that all of the other authors have read and approved the manuscript and no ethical issues involved.

\section{References}

Anton, C., \& Shikov, A. (2018). The method of personalized corporate e-learning based on personal traits of employees. Procedia Computer Science, 136 , 511-521. https://doi.org/10.1016/j.procs.2018.08.253

Chookaew, S., Panjaburee, P., Wanichsan, D., \& Laosinchai, P. (2014). A personalized e-learning environment to promote student's conceptual learning on basic computer programming. ProcediaSocial and Behavioral Sciences, 116, 815-819. https://doi.org/10.1016/j.sbspro.2014.01.303 
Daubigney, L., Geist, M., \& Pietquin, O. (2011, May). Apprentissage par renforcement pour la personnalisation d'un logiciel d'enseignement des langues. In EIAH 2011 (pp. 1-5). https://halsupelec.archives-

ouvertes.fr/file/index/docid/652516/filename/EIAH2 011_LDMGOP.pdf

El Guabassi, I., Bousalem, Z., Al Achhab, M., Jellouli, I., \& Mohajir, B. E. E. (2018). Personalized adaptive content system for context-aware ubiquitous learning. Procedia Computer Science, 127, 444-453. https://doi.org/10.1016/j.procs.2018.01.142

Gómez, S., Zervas, P., Sampson, D. G., \& Fabregat, R. (2014). Context-aware adaptive and personalized mobile learning delivery supported by UoLmP. Journal of King Saud University-Computer and Information Sciences, 26(1), 47-61. https://doi.org/10.1016/j.jksuci.2013.10.008

Huang, X. (2011). Study of personalized e-learning system based on knowledge structural graph. Procedia Engineering, 15, 3366-3370. https://doi.org/10.1016/j.proeng.2011.08.631

Kar, P., Shareef, A., Kumar, A., Harn, K. T., Kalluri, B., \& Panda, S. K. (2019). ReViCEE: A recommendation based approach for personalized control, visual comfort \& energy efficiency in buildings. Building and Environment, 152, 135-144. https://doi.org/10.1016/j.buildenv.2019.01.035

Lefevre, M. (2010, May). GEPPETO: une approche générique permettant d'adapter les activités des apprenants aux intentions pédagogiques de chaque enseignant. In 3ème Rencontres Jeunes Chercheurs en Environnements Informatiques pour l'Apprentissage Humain (RJC EIAH 2010) (pp. 35-40). https://hal.archives-ouvertes.fr/hal-01381464/

Lefevre, M., Jean-Daubias, S., \& Guin, N. (2011). PERSUA2, un modèle pour unifier le processus de personnalisation des activités d'apprentissage. In Environnements Informatiques pour l'Apprentissage Humain, Conférence EIAH'2011 (pp. 369-380). Editions de l'UMONS, Mons 2011. https://hal.archives-ouvertes.fr/hal-00605767/

Moulet, L. (2005). Revue de littérature du ePortfolio: Définitions, contenus et usages. Visant à l'intégration d'un ePortfolio dans le modèle de l'apprenant d'un système d'apprentissage en ligne. https://hal.archives-ouvertes.fr/hal-00581476/

Pane, J. F. (2017). Insights on personalized learning implementation and effects. British Columbia Teachers' Federation.
Py, D., \& Hibou, M. (2006). Représentation des connaissances de l'apprenant. https://hal.archivesouvertes.fr/hal-01434209/

Rahman, M. M., \& Abdullah, N. A. (2018). A personalized group-based recommendation approach for Web search in E-learning. IEEE Access, 6, 34166-34178. https://doi.org/10.1109/ACCESS.2018.2850376

Różewski, P., Kieruzel, M., Lipczyński, T., Prys, M., Sicilia, M. A., García-Barriocanal, E., ... \& Uras, F. (2019). Concept of expert system for creation of personalized, digital skills learning pathway. Procedia Computer Science, 159, 2304-2312. https://doi.org/10.1016/j.procs.2019.09.405

Sfenrianto, S., Hartarto, Y. B., \& Akbar, H. (2018). An adaptive learning system based on knowledge level for english learning. International Journal of Emerging Technologies in Learning (iJET), 13(12), 191-200. https://doi.org/10.3991/ijet.v13i12.8004

Soulef, M. B., \& Abdesselam, B. (2017). L'intégration d'un système de recommandation au sein d'un EIAH. Universite De Guelm. https://123dok.net/document/1y93ewyg-1integration-systeme-recommandation-seineiah.html?utm_source=related_list

Srivastava, B., \& Haider, M. T. U. (2017). Personalized assessment model for alphabets learning with learning objects in e-learning environment for dyslexia. Journal of King Saud University-Computer and Information Sciences, 32(7), 809-817. https://doi.org/10.1016/j.jksuci.2017.11.005

Szilagyi, I., Greffier, F., \& Domenget, J. C. (2011). Apprentissage personnalisé via le web sémantique. Atelier "Personnal. l'apprentissage quelles Approch. pour quels besoins, 1-8.

Tsolis, D., Stamou, S., Christia, P., Kampana, S., Rapakoulia, T., Skouta, M., \& Tsakalidis, A. (2010). An adaptive and personalized open source elearning platform. Procedia-Social and Behavioral Sciences, $9, \quad 38-43$. https://doi.org/10.1016/j.sbspro.2010.12.112

Yarandi, M., Jahankhani, H., \& Tawil, A. (2013). A personalized adaptive e-learning approach based on semantic web technology. webology, 10(2), Art110. https://repository.uel.ac.uk/item/85vx1 